\title{
Early commitments help patent pool formation
}

\author{
François Lévêque \& Yann Ménière
}

June 17, 2008

\begin{abstract}
This paper explores in what circumstances patent owners can be expected to join unilaterally a patent pool. We develop a simple model in which owners of patents reading on a standard grant licences to competing manufacturers. Manufacturers must sink a fixed cost to enter the market for standard compliant products, and are thus exposed to a hold up when royalties are set after their entry. We show that the formation of non-cooperative patent pools nearly always fails if it takes place once manufacturers have incurred fixed costs - as is usually the case. By contrast, allowing the formation of patent pools ex ante facilitates the emergence of stable non-cooperative patent pools. Such ex ante pools yield lower prices and higher licensing profits than ex post patent pools would. We discuss the policy implications of these results concerning the credibilty of licensing commitments required by standard setting bodies.
\end{abstract}

Cerna, Ecole des Mines ParisTech

leveque@ensmp.fr

meniere@ensmp.fr 


\section{Introduction}

During the last two decades, the number of patents reading on technology norms such as the DVD, MPEG or WCDMA standards has increased dramatically (Simcoe, 2005). Such patents, belonging to various owners, are selected during the standard setting process and licensed to manufacturers once the standard is set. As their number was growing, their licensing has raised twofold issues. First, double-marginalization inefficiently raises the royalties charged to manufacturers. Patent owners tend to charge excessive royalties when they grant licences separately. This induces lesser demand for standard-compliant products, but also lower profits for the patent owners themselves (Shapiro, 2000). The other problem deals with patent hold-up. Licensing usually takes place once manufacturers have sunk irreversible costs to adopt the standard. Patent owners can thus charge higher royalties, thereby creating a climate of defiance that may deter the adoption of standards in the long term (Farrell et al., 2007; Lemley \& Shapiro, 2007).

Both issues have prompted answers that do not seem fully effective. Creating patent pools which license patents jointly is a way to fix double marginalization. Yet patent pool formation often fails in practise because of free riding. It is indeed more profitable for a patent owner to hold out its patents, and take advantage of the existence of the pool to raise its own royalties (U.S. DoJ \& FTC, 2007). To prevent the hold-up problem, standard setting organizations usually require that owners make early commitments to license their patents under Resasonable and Non Discriminatory terms. However these commitments remain vague and difficult to enforce, and several recent cases $^{1}$ have shed a crude light on their ineffectivity.

In contrast, we show in this paper that binding licensing commitments are an effective way to mitigate both the hold-up and double marginalization problems. We develop a simple dynamic model that captures both issues. Competing manufacturers of standard compliant products license patents reading on a standard from $k$ different owners. Since adopting a standard entails specific investments in the technology, we consider that manufacturers must sink a fixed cost to enter the market. If licensing takes place after entry, patent owners can thus hold-up captive manufacturers and charge them higher royalties. Because of double marginalization, the royalties increase even more if patent owners set their royalties separately.

We use this setting to compare two patent pool scenarios. In the first one the

\footnotetext{
${ }^{1}$ The two most commented hold-up cases are Rambus and Qualcomm. Rambus took advantage of its involvement in the work to standardize random access memory (RAM) to word its patents in order to make sure that the new standard would infringe them, all the while leading the other members to believe that it had no patent covering the future standard. Rambus then sued the users of the standards for violating its IPR. Qualcomm is the biggest owner of patents reading on the WCDMA wireless communication standard. Broadcom and five other firms, including Nokia, filed a complaint with the European Commission against Qualcomm for abuse of a dominant position, particularly by refusing to license its patents on Fair and Reasonable terms as it had pledged to do.
} 
pool is created once the standard setting process is over, e.g. after manufacturers have sunk their fixed cost. We refer to it as the ex post scenario. The second scenario corresponds to the ex ante formation of the pool. In this case, we assume that patent owners can join a pool before the end of the standard setting process, and that this pool in turn commits on a joint royalty before the entry of manufacturers. Importantly, we assume that both commitments to join the pool and to apply the announced royalty are binding.

We study in each scenario in what circumstances patent owners can be expected to join unilaterally a patent pool. In the ex post scenario, the decision to join the pool depend on two effects. On the one hand, mitigation of the double marginalization problem benefits to all licensors, be they within or outside the pool. On the other hand, joining a pool implies profit dilution for the patent holder, since the pool behaves like a unique licensor which profit must be split between all its members. We find as expected that the second effect dominates the first one as soon as there are more than two patent owners, such that patent pools cannot spontaneously emerge.

Besides double margins mitigation and profit dilution, the patent owners' decision to join or stay out of an ex ante pool is then affected by two new and conflicting effects. On the one hand, ex ante royalty setting creates a Stackelberg pattern in which the first mover can set a higher royalty and oblige followers to lower their royalties. On the other hand, the incentive to lower royalties to mitigate double margins is reinforced by the incentive to attract new entrants. We show that the first effect dominates when the number of independent licensors is large, such an ex ante pool will always emerge. As the size of the pool increases, it will however lower its royalties because of the second effect. At equilibrium, we show that the existence of the ex ante pool always results in lower total royalties paid by manufacturers.

These findings contribute to a growing body of literature on the licensing of patents reading on technoloy standards. Shapiro (2001) and Gilbert (2004) have first pinpointed the double marginalization problem and shown that creating patent pools is a way to fix it. Lerner and Tirole (2004) and Lerner et al. (2005) show that the potential anticompetitive effects of patent pools can be avoided with appropriate provisions. Our work relates more directly to the papers of Aoki and Nagaoka (2004) and Brenner (2005). Both find in different settings that the grand coalition of all patent owners cannot emerge as a patent pool. Our analysis is consistent with their finding and complements it by shedding light on the mechanisms underlying individual hold out strategies in ex post and ex ante scenarios. The litearture on patent hold-up and standards developed more recently in the trail of antitrust cases (Swanson \& Baumol, 2005; Farrell et al., 2007; Lemley \& Shapiro, 2007). These papers defend the idea that standard setting bodies should organize ex ante competition between technologies, such that patent owners commit on royalties reflecting the outcome of ex ante competition. Our analysis provides a different and complementary interpretation of ex ante royalty setting, which emphasizes the interest of using binding commitments to set a global royalty that can then be split between patent owners. 
The rest of the paper is organized in four Sections. We introduce our basic setting in Section 2. The ex post and ex ante patent pool scenarios are analyzed in Sections 3 and 4 respectively. We conclude and discuss policy implications in Section 5 .

\section{General setting}

We consider the licensing of a technology standard to firms in a downstream sector of $n$ manufacturers competing à la Cournot. The standard embodies $k$ essential patents, each of which belongs to a different R\&D firm. The manufacturers pay a per unit royalty $R$ for the bundle of the $k$ patents. Before studying how the level of global royalty is determined, we study as a first step the downstream market in order to derive the demand for licenses.

The inverse demand function to manufacturer $i$ writes

$$
P=a-\sum_{j=1}^{n} q_{j}
$$

The unit production costs of manufacturers are noted $c$; they are symmetric and constant. Moreover manufacturers pay the per unit royalty $R$ for using the technology standard. The program of a manufacturer, given that $n$ firms compete on the downstream market, writes:

$$
\max _{q_{i}} q_{i}\left(a-q_{i}-\sum_{j \neq i} q_{j}-c-R\right)
$$

At symmetric equilibrium, the individual production $q$ and profit $\pi_{M}$ of a manufacturer are respectively

$$
\begin{aligned}
q_{M} & =\frac{x-R}{n+1} \text { where } x \equiv a-c \\
\pi_{M} & =q_{M}^{2}
\end{aligned}
$$

We assume there is an irreversible fixed cost $E$ of entry into the downstream market. This cost corresponds especially to the cost of implementing the standard. For simplicity we assume further on that $E=1$. Given a royalty level $R$, firms enter into the market until the entry profit is zero, e.g. $\pi_{M}(n)=1$. At free entry equilibrium, the number of manufacturers is thus given by

$$
n=x-R-1
$$

It can be checked easily that at free entry equilibrium we have $q_{M}=1$. From $n$ and $q$ we can derive the total production $Q$ and the price $P$ of goods on the downstream market: 


$$
\begin{aligned}
& Q(R)=n q_{M}=x-R-1=n \\
& P(R)=c+R+E
\end{aligned}
$$

We study succesively two patterns of royalty setting and patent pool formation. In the first case manufacturers enter the downstream market before the licensors announce their royalties. Patent owners have then the choice between joining a unique patent pool, or licensing their patent separately. In the second case the patent pool is created before the manufacturers enter the market. Patent owners then can either join the patent pool, or decide to announce their royalties ex post.

\section{Patent pool created after entry}

We assume in this section that all licensing decisions take place after the manufacturers have entered the market for standard-compliant goods. This implies that the patent owners cannot influence the entry of manufacturers and must take their number $n$ as given. In this context, we study whether some patent owners will agree to form a patent pool in order to set their royalties jointly.

Timing of the game:

1) manufacturers enter the market for standard compliant products

2) patent pool formation

3) the patent pool and the independent licensors set the royalties

\subsection{Independent licensors}

Let us assume that a set $L$ of $l$ firms fix their royalties $R_{l}^{i}(i \in L)$ independently, while a set $P$ of $(k-l)$ firms join a patent pool and fix a joint royalty $R_{l}^{P}$ ex post. We study the maximisation profit program of an independent licensor. The demand adressed to a licensor $i$ writes:

$$
\begin{aligned}
& Q\left(R_{l}^{i}\right)= n \frac{x-R_{l}^{i}-\bar{R}}{n+1} \\
& \text { where } \bar{R}=\left\{\begin{array}{c}
R_{l}^{P}+\sum_{j \in L \backslash i} R_{l}^{j} \text { if } i \in L \\
\sum_{j \in L} R_{l}^{j} \text { if } i \text { is the patent pool }
\end{array}\right.
\end{aligned}
$$

The patent pool appears as an $(l+1)^{t h}$ independent licensor. Maximizing the profit $R Q(R)$ of each licensor with respect to $R$ yields the following royalty at symmetric equilirbium: 


$$
\begin{aligned}
R_{l}^{i} & =\frac{x}{l+2} \equiv R_{l}^{L} \text { if } i \in L \\
R_{l}^{P} & =\frac{x}{l+2}=R_{l}^{L}
\end{aligned}
$$

We can now calculate the demand adressed to an independent licensor (including the patent pool) and their profits:

$$
\begin{aligned}
Q & =\frac{n}{n+1} \frac{x}{l+2} \\
\pi_{l}^{L} & =\frac{n}{n+1}\left(\frac{x}{l+2}\right)^{2}
\end{aligned}
$$

Members of the pool share equally the profit made by the pool. Since the total profit of the pool equals the profit of an independent licensor, it is clear that for a given $l$, a pool member always gets less than an independent licensor. The individual profit of a pool member writes:

$$
\pi_{l}^{P}=\frac{\pi_{l}^{i}}{k-l}=\frac{1}{k-l} \frac{n}{n+1}\left(\frac{x}{l+2}\right)^{2}
$$

Proposition 1 The profit of an independent licensor is decreasing in $l$. The profit of a member of the pool is decreasing in $l$ on $\left[0, \frac{2}{3}(k-1)\right]$ and increasing on $\left.] \frac{2}{3}(k-1), k-1\right]$.

Proof. See Appendix.

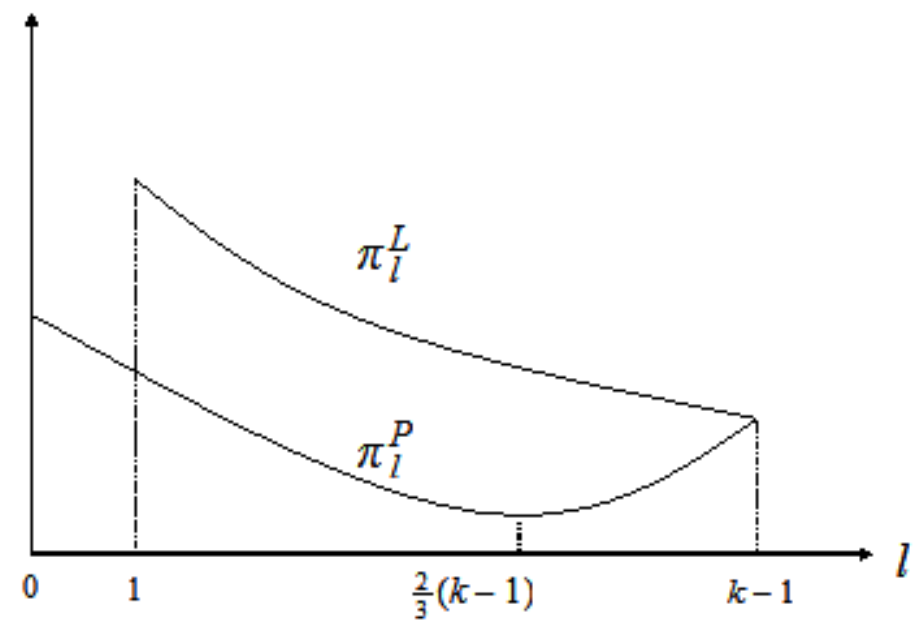

Figure 1: Licensing profits with an ex post patent pool. 
Proposition 1 is illustrated in Figure 1. A patent pool helps mitigate the double marginalization problem, which benefits not only the pool but also independent licensors. Conversely, the smaller the pool, the smaller the individual profit of independent licensors. The effect of the number of independent licensors on the profit of a pool member is more subtle. On the one hand, the decrease in the size of the pool worsens the double marginalization effect, and hence the total profit made by the pool. On the other hand it implies that the total profit of the pool will be split between less members, which tends to rise their individual shares. Proposition 1 shows that the first effect prevails when the pool is large while there are few independent licensors $\left(l<\frac{2}{3}(k-1)\right)$. In particular, a patent pool including the grand coalition of all patent owners $(l=0)$ generates more individual profits than the absnece of patent pool $(l=k-1)$.However, as the number of independent licensors reaches about two thirds of the patent owners, the dilution effect becomes more important, so that one more defection actually increases the profit of those who stay in the pool when $l>\frac{2}{3}(k-1)$.

\subsection{Patent pool formation}

Although the formation of a patent pool helps mitigate the double marginalization problem, it may be more profitable for an individual patent owner to stay outside the pool. Indeed, it can thereby benefit from the double margins mitigation enhanced by the pool, without having to share its licensing profits with other patent holders. We focus now on this hold-out problem, by studying the individual incentives of patent owners to join or quit a patent pool.

We study as a first step whether a pool can form as a Nash equilibrium. Starting from a situation in which all $k$ patent owners license separately, a pool will emerge if two patent owners decide to create it, e.g. if $\pi_{k-2}^{P}>\pi_{k-1}^{L}$. Figure 1 clearly shows that moving away from the situation where all patents are licensed separately implies a profit increase for those remaining independent licensors (due to the mitigation of double marginalization) and a net profit loss for the pool members (due to the dilution effect). In this context Proposition 2 shows that two patent owners will find an interest in cooperating only if there is no independent licensor remaining, e.g. if $k=2$.

Proposition 2 Two patent owners will create a pool if $k=2$. If $k>2$ two patent owners will never start a pool.

Proof. See Appendix.

It may be exagerately pessimistic to assume that more than two patent owners cannot coordinate to create a pool. It is more realistic to allow instead for $k-l$ patent owners to coalize in order to create a pool, and to check whether such a coalition can be a Nash equilibrium. Considering a coalition of $(k-l)$ patent owners, this is the case if an independent licensor prefers to stay out of the pool (e.g., if $\pi_{l}^{L}<\pi_{l-1}^{P}$ ) and, conversely, if a member of the coalition prefers 
to stay in (e.g., if $\pi_{l+1}^{L}>\pi_{l}^{P}$ ). Checking stability for all $k>1$ and $l<k$ yields the following Proposition.

Proposition 3 If $k \geq 4$, there is no Nash proof coalition. If $k \in\{2,3\}$, the grand coalition is the only Nash proof coalition.

Proof. See Appendix.

A patent pool based on a coalition can be a Nash equilibrium only if there are less than 2 or 3 patent owners. Otherwise, a coalition of two or more patentees forming a patent pool is always subject to strategic instability. The stability of the patent pool with 2 or 3 patent owners is due to the absence or limited number (one) of independent licensors that may be tempted to free ride on the others' effort to decrease royalties. When $k=3$, it is interesting to observe that two patent owners will not spontaneously start a patent pool because the outside position of the third patentee is more profitable. This problem generalizes when $k>3$ : it is always more profitable to hold out one's patent instead of joining a pool of whatever size.

\section{Patent pool created before entry}

We have seen in the previous Section that patent pools created after the entry of manufacturers are subject to instability due to patent hold-out, which prevents their spontaneous formation when there are more than two patent owners. We show in this Section that the problem of patent pool formation can be fixed if patent owners are allowed to make binding commitments on a joint license before manufacturers enter the market. Note that since commitments are made during the standard setting process, patent owners do not contract them with manufacturers, but with the standard setting body. Accordingly, independent patent owners are not able to make binding ex ante commitments. As in the previous Section, we assume that a set $L$ of $l$ firms fix their royalties independently after the manufacturers have entered the market. However we now let a set $A$ of $(k-l)$ firms join a patent pool and fix a joint royalty $R_{l}^{A}$ before manufacturers invest $E$.

Timing of the game:

1) patent pool formation

2) the patent pool commits on a royalty level

3) manufacturers enter the market for standard compliant products

4) independent licensors set their royalties

\subsection{Licensing profits}

We study as a first step the maximisation profit program of an independent licensor given $R_{l}^{A}$. The independent licensor $i \in L$ fixes its royalty after the entry of manufacturers. Hence it perceives the number of manufacturers as 
an exogenous variable. Maximizing the profit $R_{l}^{i} Q\left(R_{l}^{A}+\sum_{j \in L \backslash i} R_{l}^{j}\right)$ of each independent licensor with respect to $R_{l}^{i}$ yields the following royalty per licensor at symmetric equilibrium:

$$
R_{l}^{L}\left(R_{l}^{A}\right)=\left\{\begin{array}{c}
\frac{x-R_{l}^{A}}{l+1} \text { if } l \in[1, k-1] \\
\frac{x}{k+1} \text { if } l=k
\end{array}\right.
$$

Observe that $R_{l}^{L}\left(R_{l}^{A}\right)$ and $R_{l}^{A}$ are strategic substitutes. Using (1), we can derive from $R_{l}^{L}\left(R_{l}^{A}\right)$ and $R_{l}^{A}$ the number of manufacturers that enter the market for standard compliant products in presence of a patent pool, (e.g. when $l \in$ $[1, k-1])$.

$$
n\left(R_{l}^{A}\right)=\left\{\begin{array}{c}
\frac{x-R_{l}^{A}-(l+1)}{l+1} \text { if } l \in[1, k-1] \\
\frac{x-(k+1)}{x} \text { if } l=k
\end{array}\right.
$$

The number of entrants $n\left(R_{l}^{A}\right)$ is an endogenous variable for the patent pool when it commits on a royalty $R_{l}^{A}$ before the entry of manufacturers. By (2), we know that at the first stage, the patent pool thus maximizes its profit $\Pi_{l}^{A}\left(R_{l}^{A}\right)=R_{l}^{A} n\left(R_{l}^{A}\right)$. This profit is maximized by the royalty $\bar{R}_{l}^{A}$ such that:

$$
\bar{R}_{l}^{A}=\frac{x-(l+1)}{2} \text { if } l \in[1, k-1]
$$

Noting that $n=\frac{x-(k+1)}{x}$ if $l=k$ and using (6) in (4) in turn imply that the royalty $\bar{R}_{l}^{L}$ set by an independent licensor is:

$$
\bar{R}_{l}^{L}=\left\{\begin{array}{c}
\frac{1}{2}\left(\frac{x}{l+1}+1\right) \text { if } l \in[1, k-1] \\
\frac{x}{k+1} \text { if } l=k
\end{array}\right.
$$

Observe that when $l \in[1, k-1]$, its value does not affect the equilibrium royalty of the pool and of independent licensors in the same way. To ensure that non-negative royalty $\bar{R}_{l}^{A}$ and demand $n\left(\bar{R}_{l}^{A}\right)$ are possible in this case, we will assume further on that $x>k+1$.

\section{Hypothesis 1: $x>k+1$}

It is interesting to observe that under Hypothesis 1 we have $\bar{R}_{k-1}^{A}=(x-k) / 2>$ $R_{k-1}^{P}=x /(k+1)$. In other terms, a one-member patent pool charges a higher royalty when it is able to commit ex ante. This asymmetry actually reflects a Stackelberg pattern allowing the first mover to preempt a larger share of the licensing profits. Consider in turn the grand-coalition patent pools in the ex post and ex ante scenarios. We can check easily that $\bar{R}_{0}^{A}=(x-1) / 2<R_{0}^{P}=x / 2$. 
The grand coordination thus charges lower royalties in the ex ante scenario. Given that the double marginalization problem is completely solved in both scenarios, the lower royalty charged by the ex ante pool is due to its incentive to promote the entry of more manufacturers. These Stackelberg and Entry Promotion effects paly in opposite directions. We will see below that their respective weighs depend on the size of the ex ante patent pool.

Using (5), (6) and (7), we can now reexpress the profit $\bar{\pi}_{l}^{L}$ and $\bar{\pi}_{l}^{A}$ of an independent licensor and the profit of a member of the patent pool:

$$
\begin{aligned}
& \bar{\pi}_{l}^{L}=\left\{\begin{array}{c}
\frac{x^{2}-(l+1)^{2}}{4(l+1)^{2}} \text { if } l \in[1, k-1] \\
\left(\frac{x}{k+1}\right)^{2}-\frac{x}{k+1} \text { if } l=k
\end{array}\right. \\
& \bar{\pi}_{l}^{A}=\frac{1}{k-l} \frac{(x-l-1)^{2}}{4(l+1)} \text { if } l \in[1, k-1]
\end{aligned}
$$

Comparing these profits yields the following results:

Proposition 4 The profit shapes are the following:

- The profit $\bar{\pi}_{l}^{L}$ of an independent licensor is decreasing in $l$ on $[0, k-1]$.

- When $x>\frac{k}{k-1}(k+1)$, the profit $\bar{\pi}_{l}^{A}$ is inverse-U-shaped in l on $[0, k-1]$. It reaches a minimum in $\bar{l}=\frac{(k-1) x+1+k}{2 x-k-1}$.

- When $x \leq \frac{k}{k-1}(k+1)$, the profit $\bar{\pi}_{l}^{A}$ of a member of the pool is decreasing in $l$ on $[0, k-1]$.

Corollary 5 When $x>\frac{k}{k-1}(k+1)$, we have:

- $\bar{\pi}_{k-1}^{A}>\bar{\pi}_{k}^{L}>\bar{\pi}_{k-1}^{L}$,

- $\bar{\pi}_{l}^{A}>\bar{\pi}_{l}^{L}$ if $l \in[\bar{l}, k-1]$,

- $\bar{\pi}_{\bar{l}}^{A}=\bar{\pi}_{\bar{l}}^{L}=\bar{\pi}_{k}^{L}$,

- $\bar{\pi}_{l}^{A}<\bar{\pi}_{l}^{L}$ if $l \in[0, \bar{l}]<\bar{l}$.

Corollary 6 When $x \leq \frac{k}{k-1}(k+1)$, we have:

- $\bar{\pi}_{k-1}^{L}>\bar{\pi}_{k-1}^{A}>\bar{\pi}_{k}^{L}$,

- $\bar{\pi}_{l}^{A} \leq \bar{\pi}_{l}^{L}$ for all $l \in[0, k-1]$.

Proof. See Appendix.

Proposition 4 is illustrated in Figures 2 and 3 below. Figure 2 corresponds to the condition $x>\frac{k}{k-1}(k+1)$ denoting a large market for standard compliant products. Observe first the difference between $l=k$ and $l=k-1$. In the first 
case all owners grant independent licences ex post, which maximizes the double marginalization effect. If one of them moves ex ante, it will benefit from a first mover (Stackelberg) advantage and charge a higher royalty, thereby obliging the other licensors to decrease their royalties (with a net increasing effect on the sum of all royalties). The first mover thus increases its profit while the others lose money (since individual royalties are strategic substitutes). There is always an incentive to start forming a patent pool.

If $l \in[0, k-1]$, we can firstly observe that the profit of an independent licensor is still decreasing in the number of such licensors. The profit of a member of the pool is also inverse-U-shaped in $l$. This shape reflects the balance between the gain from double margins mitigation and entry promotion on the one hand, and the opportunity cost associated with profit dilution on the other hand. Contrary to the ex post case, note that the profit of a pool member now crosses $\bar{\pi}_{l}^{L}$ at its minimum. At this point $\bar{l}$, the profit of all licensors, be they within or outside the pool, is equal to their profits in absence of a pool. This corresponds to a balance between the royalty-increasing (Stackelberg) and royalty decreasing effects of the patent pool. Beyond that threshold (e.g., for $l<\bar{l}$ ), the profit of both independent licensors and members of the pool increases in the size of the pool, thereby denoting that the royalty decreasing effects dominate.

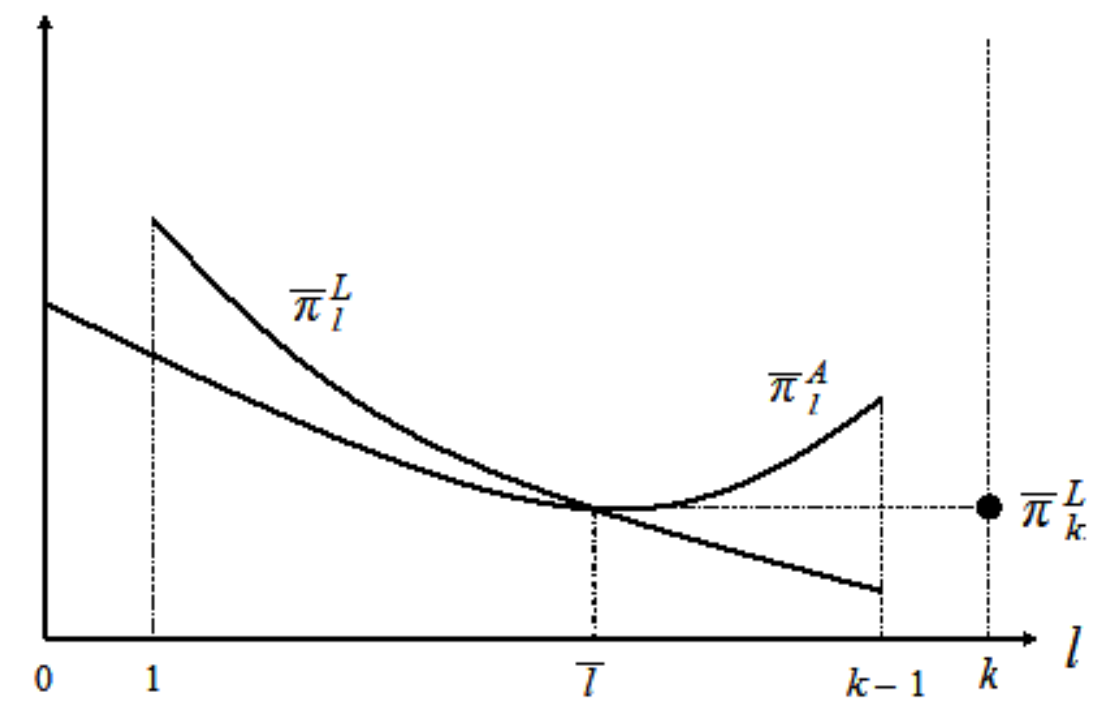

Figure 2: Licensing profits with an ex ante patent pool when $x>\frac{k}{k-1}(k+1)$.

Figure 3 corresponds to the condition $k+1 \leq x \leq \frac{k}{k-1}(k+1)$ denoting a small market for standard compliant products. Both $\bar{\pi}_{l}^{L}$ and $\bar{\pi}_{l}^{A}$ are decreasing in $l \in[0, k-1]$, for the condition implies that $\bar{l}>k-1$. Figure 3 thus corresponds to the left hand side of Figure 2, and it is not surprising that $\bar{\pi}_{l}^{L}>\bar{\pi}_{l}^{A}$. Since $\bar{\pi}_{\bar{l}}^{A}=\bar{\pi}_{\bar{l}}^{L}=\bar{\pi}_{k}^{L}$, it is obvious as well that $\bar{\pi}_{k-1}^{L}>\bar{\pi}_{k-1}^{A}>\bar{\pi}_{k}^{L}$. 


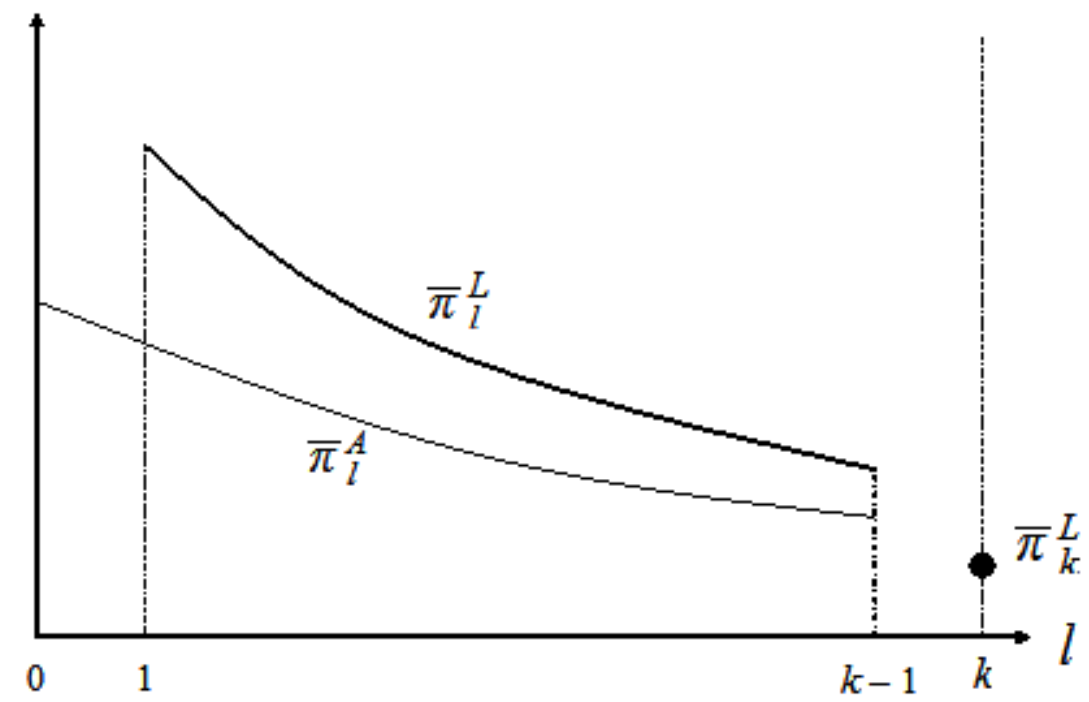

Figure 3: Licensing profits with an ex ante patent pool when $x<\frac{k}{k-1}(k+1)$.

We explore more systematically the formation of ex ante patent pools in the next Subsection.

\subsection{Patent pool formation}

We study now whether a patent pool will emerge if it is created ex ante. We establish as a first step that a grand coalition of all patent owners cannot be a Nash stable ex ante patent pool.

Proposition 7 For $k \geq 4$, the grand coalition is not Nash proof. For $k=3$, it is Nash proof iff $x \leq 3$. For $k=2$ it is always Nash proof.

Proof. See Appendix.

As with ex post patent pool, Proposition 5 establishes that a grand patent pool cannot constitute a Nash equilibrium. The instability is due to the incentives for individual patent owners to hold-out their patents and free ride on the low royalties charged by the pool. In this context, the grand patent pool is stable only if there is no or limited possibility of free riding on the pool, e.g. if $k=2$ or $k=3$.

Although the grand patent pool can never emerge as a Nash equilibrium for $k>3$, the following result establishes that a pool will always emerge if it can be created ex ante.

Proposition 8 When the grand coalition is not Nash Proof, there a unique Nash proof ex ante coalition defined by $l^{*}$ and such that $0<l^{*}<\bar{l}$. This equilibrium implies a decrease in total royalties with respect to the absence of patent pool. 
Proof. See Appendix.

Proposition 6 firstly establishes that a patent pool will always be created, and that it won't rally all patent owners if $k \geq 4$ or $x \leq k=3$. The size $k-l^{*}$ of the equilibrium patent pool is such that $l^{*}<\bar{l}$. This implies that the royalty decreasing effects of the pool then dominate its royalty increasing effects. In the end, the patent owners will split in two categories. On the one hand a group of patent owners will join the pool and charge low royalties first hand in order to derive profits from a larger number of licensees. On the other hand, the rest of the patent owners will prefer to stay out of the pool in order to charge larger royalties ex post.

It is worth insisting on the fact that this pattern corresponds to a stable Nash equilibrium. In absence of a pool, some patent owners will always start forming a pool to benefit of a first mover advantage. They will then be joined by others until the equilibrium size is reached. Conversely, a grand patent pool will always see some of its members drop out until the equilibrium size is reached. In the end, the Nash stable patent pool will entail larger profits to its members and non-members, by fostering the entry of more licensees, and by mitigating the double marginalization problem. Since lower royalties and more entry imply lower prices and more variety of end products, the formation of the ex ante patent pool is also clearly beneficial to end consumers.

\section{Conclusion}

We have explored in this paper in what circumstances patent owners can be expected to join unilaterally a patent pool. We have developed a simple model in which owners of patents reading on a standard grant licences to competing manufacturers. Assuming that manufacturers must sink a fixed cost to enter the market for standard compliant products, we have compared two timings of patent pool formation. We have shown that the formation of non-cooperative patent pools nearly always fails if it takes place once manufacturers have incurred fixed costs. By contrast, a stable non-cooperative patent pool can emerge ex ante if patent owners can make binding commitments to join it. We have moreover shown that such an ex ante pool yields lower prices and higher licensing profits than ex post patent pools would.

This analysis improves the understanding of patent pools in different ways. It firstly characterizes the hold out problem and its consequence, namely that non cooperative patent pools cannot emerge at equilibrium in an ex post scenario. It also highlights an intrinsinc inefficiency of ex post patent pools, admitting they can fix the double marginalization problem. When standards entail irreversible adoption costs, such pools indeed fail in attracting enough licensees, because of a hold-up problem. High royalties charged to captive licensees then result in higher product prices and lower profits for licensors. This finding has an important implication. Provided it can make credible commitments, a patent pool created at an earlier stage of the standard setting process - that is before 
manufacturers sink entry costs - allows licensors to promote entry. By generating additional profits, this reinforces their incentives to join a pool. It thus facilitates the spontaneous formation of pools that are both more efficient and robust to patent hold out.

These results have interesting policy implications concerning price discussions in standard setting bodies. Until recently, antitrust authorities have been suspicious about ex post patent pools, let alone early price discussion in standard setting bodies. While the pro-efficiency effects of patent pools have already been demonstrated and accepted by antitrust authorities, our results suggest that they should as well consider accepting, and even encouraging, early licensing agreements in standard setting bodies. Besides the reluctance of public authorities, the absence of such agreements until very recently can also be explained by other factors. Standard setting organizations have long been purely technical bodies, and licensing issues have arised only recently, in the trail of the patent surge they experienced. Another important factor deals with the credibility of licensing commitments. Early price announcements would take place before all future licensees can be identified, and therefore raise a problem of credibility. Standard setting bodies may thus have an important role to play to enforce such commitments. The recently adopted intellectual property policy of the VITA standard setting body is a good illustration. VITA stands for VMEbus International Trade Association; it creates standards for certain computer bus architecture. Its policy includes a special provision that requires its members to disclose maximum royalty rates they will demand for their essential patents. If a patent owner fails to comply with his royalty commitment, he is forced to license his intellectual property right on a royalty-free basis.

The analysis carried out in this paper has limitations that could be addressed in subsequent works. We have firstly assumed that all patent owners held symmetric patent portfolios, which may not be true in practise. Introducing asymmetric patents would not change the analysis of ex post licensing, since all patent holders would still enjoy monopoly power on an essential input. However, it may be interesting to introduce asymmetry in the analysis of the ex ante patent pool. Allocating profits in function of the ex ante value of the patents held by the pool's members, as suggested by Swanson \& Baumol (2005) and Lemley \& Shapiro (2007), would indeed modify their incentives to join the pool. We can especially expect that firms with larger patent portfolios would be more willing to join an ex ante pool. We also assume that all patent owners are pure $R \& D$ firms that do not operate as manufacturers on the market for standard compliant products. This assumption contrasts with most standards in which key patent owners are often also downstream manufacturers. Introducing such vertically integrated firms would certainly enrich the analysis. We have also neglected the role of uncertainty in the licensing decision. By assuming that patent owners could perfectly predict ex ante the size of the market for standard compliant products and the future number of entrants, we have ruled out a possible deterrent to ex ante licensing ${ }^{2}$.

${ }^{2}$ We have introduced uncertainty in another, simpler model with a unique licensor, and 


\section{Bibliography}

\section{References}

[1] Aoki, R., Nagaoka, S. (2004) "Coalition Formation for a Consortium Standard through a Standard Body and a Patent Pool" Working paper, Institute of Innovation Research, Hitotsubashi University.

[2] Brenner, S. (2006) "Optimal Formation Rules for Patent Pools", mimeo.

[3] Farrell J., J. Hayes, C. Shapiro, T. Sullivan (2007) "Standard Setting, Patents, and Hold-up" Antitrust Law Journal, forthcoming.

[4] Gilbert, R. (2004) "Antitrust for Patent Pools: A Century of Policy Evolution," Stanford Technology Law Review, available at http://stlr.stanford.edu/STLR/Core_Page/.

[5] Lemley M. A. and C. Shapiro (2007) "Patent Holdup and Royalty Stacking" Texas Law Review.

[6] Lerner J. and Tirole J. (2004) "Efficient Patent Pools" American Economic Review, 94:3, 691-711.

[7] Lerner, J., Strojwas, M, Tirole, J. (2005) "The Design of Patent Pools: the Determinants of Licensing Rules" IDEI Working Paper n. 187.

[8] Lévêque, F., Ménière, Y. (2007) "Licensing Commitments in Standard Setting Organizations", Cerna working paper.

[9] Shapiro C (2001) "Navigating the Patent Thicket: Cross Licences, Patents Pools, and Standard Setting", in A. Jaffe, J. Lerner et S. Stern (Ed.), Innovation Policy and the Economy, Vol 1, MIT Press.

[10] Simcoe, T. (2005) "Explaining the Increase in Intellectual Property Disclosure", working paper.

[11] Swanson D. and W. Baumol (2005) "Reasonable and Nondiscriminatory (RAND) Royalties, Standards Selection, and Control of Market Power" Antitrust Law Journal 73:1.

shown that licensing schemes based on royalty caps provide interesting compromises between ex ante and ex post licensing (Lévêque \& Ménière, 2007). 


\section{Appendix}

\section{Proof of Proposition 1}

The Proof is obvious as regards independent licensors. The derivative of the profit of a member of the pool with respect to $l$ writes:

$$
\frac{\partial \pi_{l}^{P}}{\partial l}=\frac{n}{n+1} \frac{(3 l-2 k+2) x^{2}}{(k-l)^{2}(l+2)^{3}}>0
$$

this expression is positive if:

$$
3 l-2 k+2>0 \Leftrightarrow l>\frac{2}{3}(k-1)
$$

The term on the left hand side is more increasing than the term on the right hand side, its initial value is smaller (for $l=0$ ) and its final value is larger (for $l=k)$.

\section{Proof of Proposition 2}

The initial case in which all patent owners license separately is defined by $l=$ $k-1$ and $\pi_{k-1}^{L}=\pi_{k-1}^{P}$ (e.g., the "pool" includes only one patent owner). Starting from there, another patent owner has an incentive to join the pool if $\pi_{k-2}^{P}>\pi_{k-1}^{L}$. These profits write respectively as follows:

$$
\begin{aligned}
\pi_{k-1}^{L} & =\frac{n}{n+1}\left(\frac{x}{k+1}\right)^{2} \\
\pi_{k-2}^{P} & =\frac{n}{n+1} \frac{1}{2}\left(\frac{x}{k}\right)^{2}
\end{aligned}
$$

It follows that $\pi_{k-2}^{P}>\pi_{k-1}^{L}$ if:

$$
(k+1)^{2}>2 k^{2} \Longleftrightarrow-k^{2}+2 k+1>0
$$

It can be checked easily that the polynom on the right hand side is negative for all $k \geq 3$, and positive only for $k=2$.

\section{Proof of Proposition 3}

Given a number $l$ of independent licensors, a member of the pool has an incentive to defect if $\pi_{l}^{i}>\pi_{l-1}^{p}$. These profits write respectively as follows:

$$
\begin{aligned}
\pi_{l}^{L} & =\frac{n}{n+1}\left(\frac{x}{l+2}\right)^{2} \\
\pi_{l-1}^{P} & =\frac{n}{n+1} \frac{1}{k-l+1}\left(\frac{x}{l+1}\right)^{2}
\end{aligned}
$$


Hence we have $\pi_{l}^{L}>\pi_{l-1}^{P}$ if:

$$
(l+1)^{2}>\frac{1}{k-l+1}(l+2)^{2}
$$

for $l=0$, it can be checked easily that condition (10) holds only if $k>3$. In other terms, the grand coalition of all patent owners within a patent pool is not stable if $k>2$.

for $l=1$ condition (10) writes $k>2.25$, which also implies that a pool with $k-1$ members is not stable iff $k>2$.

Observe now that condition (10) can be expressed as follows:

$$
\left(\frac{l+2}{l+1}\right)^{2}<k+1-l
$$

The derivative wrt $l$ of the right hand side is $(-1)$, while the derivative of the left hand site writes:

$$
-2 \frac{l+2}{(l+1)^{3}}<0
$$

By comparing both derivatives, we can show that:

$$
\begin{aligned}
-2 \frac{l+2}{(l+1)^{3}} & <-1 \\
l(l+2)(l+1) & \Longleftrightarrow 3
\end{aligned}
$$

Hence the left hand side is more downward sloping than the right hand side for all $l \geq 1$. Since we also know that condition (11) holds for $l=1$ when $k>2$, we can conclude that condition (11) also holds for $l \geq 1$ when $k>2$.

\section{Proof of Proposition 4}

It is obvious that $\bar{\pi}_{l}^{P}$ is decreasing in $l$. We can moreover check that:

$$
\frac{\partial \Pi_{l}^{A}\left(\bar{R}_{l}^{A}\right)}{\partial l}=-\frac{x^{2}-(l+1)^{2}}{4(l+1)^{2}}=-\bar{\pi}_{l}^{p}<0
$$

Noting $\widehat{\Pi}_{l}^{A} \equiv \Pi_{l}^{A}\left(\bar{R}_{l}^{A}\right)$, we can derive the following result:

$$
\begin{aligned}
\frac{\partial \bar{\pi}_{l}^{A}}{\partial l} & =\frac{1}{(k-l)^{2}}\left[(k-l) \frac{\partial \widehat{\Pi}_{l}^{A}}{\partial l}+\widehat{\Pi}_{l}^{A}\right]<0 \\
\bar{\pi}_{l}^{P} & >\bar{\pi}_{l}^{A}
\end{aligned}
$$

The derivative of $\bar{\pi}_{l}^{A}$ with respect to $l$ writes as follows:

$$
\frac{\partial \bar{\pi}_{l}^{A}}{\partial l}=\frac{1}{4} \frac{(x-l-k-k l-k x+2 l x-1)(x-l-1)}{(l-k)^{2}(l+1)^{2}}
$$


so that the sign of $\frac{\partial \bar{\pi}_{l}^{A}}{\partial l}$ depends on:

$$
x-l-k-k l-k x+2 l x-1<0
$$

We have:

$$
\begin{aligned}
x-l-k-k l-k x+2 l x-1 & <0 \\
& \Leftrightarrow \\
l & <\frac{(k-1) x+1+k}{2 x-k-1} \equiv \bar{l}
\end{aligned}
$$

We can check easily that $\bar{l}>0$. Moreover we have:

$$
\begin{aligned}
\bar{\pi}_{0}^{A} & <\bar{\pi}_{0}^{P} \\
& \Leftrightarrow \\
x-1 & <k(x+1)
\end{aligned}
$$

wich is always true, and

$$
\begin{aligned}
\bar{\pi}_{k-1}^{A} & >\bar{\pi}_{k-1}^{L} \\
& \Leftrightarrow \\
x & >\frac{k}{k-1}(k+1)
\end{aligned}
$$

Hence $\bar{\pi}_{l}^{A}$ is strictly decreasing on $[0, k-l]$ when $x \leq \frac{k}{k-1}(k+1)$, and inverseU-shaped when $x>\frac{k}{k-1}(k+1)$.

Finally simple calculation shows that

$$
\bar{R}_{\bar{l}}^{L}=\bar{R}_{k}^{L}=\frac{x}{k+1}
$$

Since $\bar{\pi}_{\bar{l}}^{A}=\bar{\pi}_{\bar{l}}^{L}$, we can moreover conclude that $\frac{\bar{R}_{\bar{l}}^{P}}{k-\bar{l}}=\bar{R}_{\bar{l}}^{L}$, such that

$$
\overline{l R}_{\bar{l}}^{L}+\bar{R}_{\bar{l}}^{P}=k \bar{R}_{k}^{L}
$$

It follows that the licensors face the same demand at $l=\bar{l}$ than at $l=k$, and that $\bar{\pi}_{\bar{l}}^{A}=\bar{\pi}_{\bar{l}}^{L}=\bar{\pi}_{k}^{L}$.

\section{Proof of Proposition 5}

We have

$$
\begin{aligned}
& \bar{\pi}_{0}^{A}=\frac{(x-1)^{2}}{4 k} \\
& \bar{\pi}_{1}^{P}=\frac{x^{2}-4}{16}
\end{aligned}
$$


When the ex ante patent pool includes all patent owners, the incentive for one of them to drop out writes:

$$
\begin{aligned}
\bar{\pi}_{1}^{P}-\bar{\pi}_{0}^{A} & =\frac{x^{2}-4}{16}-\frac{(x-1)^{2}}{4 k} \\
& =\frac{1}{16}\left\{(x-1)(x+1)-\frac{4(x-1)^{2}}{k}-3\right\} \\
& >0 \text { for } k>3 \\
\text { ind for } k & =3 \\
& <0 \text { for } k=2
\end{aligned}
$$

This expression is positive if:

$$
\begin{aligned}
(x-1)(x+1)-\frac{4(x-1)^{2}}{k}-3 & >0 \\
(x-1)\left[(x+1)-\frac{4(x-1)}{k}\right] & \Rightarrow 3
\end{aligned}
$$

It can be checked easily that this is always true for $k>3$, and never true for $k=2$. For $k=3$, condition (12) rewrites:

$$
-x^{2}+8 x-16=0>0
$$

This polynom has a unique root $x^{*}=4$. Hence when $k=3$ the grand patent pool is stable iff $x \leq 3$.

\section{Proof of Proposition 6}

We know that

$$
\begin{aligned}
\bar{\pi}_{l}^{P} & =\frac{x^{2}-(l+1)^{2}}{4(l+1)^{2}} \\
\bar{\pi}_{l-1}^{A} & =\frac{(x-l)^{2}}{4 l(k-l+1)}, \quad l>0
\end{aligned}
$$

The incentive to join (or quit) a pool thus writes:

$$
\bar{\pi}_{l}^{P}-\bar{\pi}_{l-1}^{A}=\frac{x^{2}-(l+1)^{2}}{4(l+1)^{2}}-\frac{(x-l)^{2}}{4 l(k-l+1)}
$$

And a pool is a Nash equilibrium if:

$$
\begin{aligned}
\bar{\pi}_{l}^{P} & =\bar{\pi}_{l-1}^{A} \\
& \Leftrightarrow
\end{aligned}
$$

$l^{3}(2 x-k-1)+l^{2}\left(4 x-2 k-2 x^{2}-2\right)+l\left(2 x-k-2 x^{2}+x^{2}(k+1)-1\right)-x^{2}=0$

A Mapple solving of this polynom shows that it has a unique root in $\mathbb{R}$. Given that $\bar{\pi}_{l}^{P}$ and $\bar{\pi}_{l-1}^{A}$ are continuous on $[1, k]$, that $\bar{\pi}_{1}^{P}>\bar{\pi}_{0}^{A}$ (for $k>3$ ) and that $\bar{\pi}_{\bar{l}-1}^{A}>\bar{\pi}_{\bar{l}}^{P}$, this root necessarily belongs to $[1, \bar{l}]$ when $k>3$. 